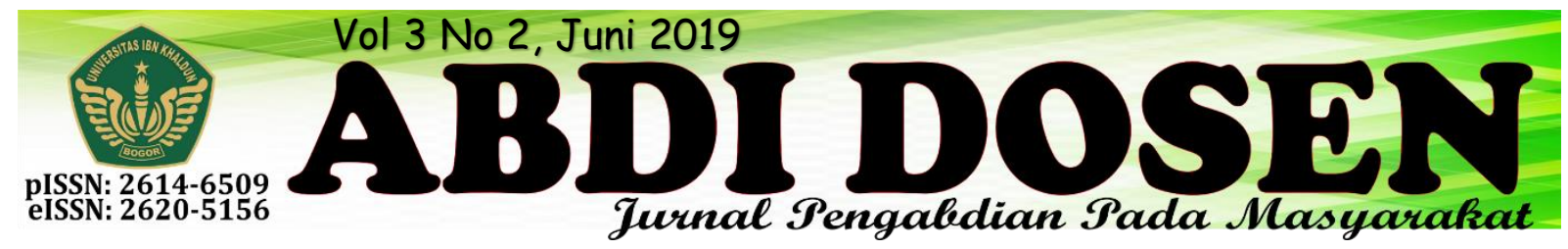

\title{
PROGRAM BINA LINGKUNGAN MELALUI PEMBANGUNAN MCK DI DESA CIBUNTU KAMPUNG CIBOYONG
}

\author{
Ichayuen Avanty ${ }^{1}$, Arbain ${ }^{2}$ \\ ichayuen@uika-bogor.ac.id \\ Fakultas Kesehatan Universitas Ibn Khaldun ${ }^{1}$, Mahasiswa KKN Kelompok 15 Tahun $2018^{2}$
}

\begin{abstract}
ABSTRAK
Kesehatan merupakan hal yang penting dalam kehidupan kita, namun perlu disadari bahwa kesehatan akan sangat bergantung dengan kondisi lingkungan di sekitar kita. Lingkungan yang bersih dan sehat maka akan menciptakan kesehatan yang baik untuk semua orang. Pentingnya kebersihan lingkungan perlu di galangkan kembali karena kebersihan lingkungan di beberapa tempat masih kurang bahkan bisa dikatakan belum mencapai derajat kesehatan, seperti fasilitas sanitasi mandi, cuci, kakus (MCK) merupakan fasilitas yang dibutuhkan sebagian warga didaerah tertentu. Menurut pengamatan kami di Kampung Ciboyong Desa Cibuntu Kecamatan Ciampea Kabupaten Bogor sudah memiliki fasilitas MCK yang memadai akan tetapi kami mendapati kurang terawatnya fasilitas tersebut dikarenakan masih banyak warga yang belum peduli dengan kebersihan MCK ditempat mereka tinggal. Karena itu, kami berinisiatif untuk merenovasi MCK yang sudah tidak layak pakai. Dengan harapan warga Kampung Ciboyong dapat menggunakan MCK kembali dan warga peduli dengan kebersihan fasilitas MCK yang mereka miliki.
\end{abstract}

\section{Kata Kunci : Kesehatan, Sanitasi, MCK}

\section{PENDAHULUAN}

\section{Latar Belakang}

Kuliah Kerja Nyata adalah bagian dari sistem Pendidikan Tinggi yang menempatkan mahasiswa di luar kampus agar mahasiswa hidup ditengah - tengah masyarakat bersama masyarakat untuk membantu dan mendampingi masyarakat memanfaatkan potensi sumber daya alam lokal dan sumber daya manusia yang ada untuk mengatasi permasalah masyarakat dalam kurun waktu tertentu. KKN Tematik Terintegrasi Universitas Ibn Khaldun Bogor merupakan salah sebuah tuntutan/ kewajiban bagi mahasiswa semester VI. Sasaran KKN bagi masyarakat yakni untuk meningkatkan kesadaran masyarakat dengan berperan aktif dalam mengembangkan produktifitas sumber daya pembangunan sesuai dengan fasilitas yang dimiliki.

Kegiatan KKN Terintegrasi Universitas Ibn Khaldun Bogor tahun 2018 merupakan salah satu kegiatan dengan pendekatan community development, dimana pada pelaksanaan kegiatan ini melakukan proses perencanaan sekaligus aksi program Pendampingan masyarakat baik pada aspek sosial, ekonomi, kesehatan, pendidikan, hukum, dan agama maupun teknologi tepat guna secara terpadu.

Desa Cibuntu Kecamatan Ciampea merupakan salah satu tempat yang di pilih 
dan ditunjuk LPPM untuk menjadi tempat pelaksanaan kuliah kerja nyata yang bertemakan Tematik Terintegrasi. Anggota posko 15 berjumlah 13 orang yang berasal dari fakultas dan jurusan yang berbeda beda.

Berdasarkan hasil survey yang dilakukan di Desa Cibuntu, dipilihlah satu kampung yaitu Kampung Ciboyong dengan RW sasaran RW 03 yang berjumlah 3 RT. Desa Cibuntu dan Kampung Ciboyong mempunyai masyarakat yang heterogen atau beragam. Sehingga dalam penyusunan serta perencanaan suatu program disesuaikan dengan kondisi, situasi dan potensi yang dimiliki oleh lokasi setempat. Setelah melihat hasil survey dan menganalisis daerah maka Tim KKN Posko 15 di tempatkan di Desa Cibuntu tepatnya dikampung Ciboyong RW 03 memilih untuk menyusun program yang mencakup empat pilar utama yaitu, Pendidikan, Kesehatan, Ekonomi dan Teknik.

Adapun program yang direncanakan dari pilar pendidikan adalah mengadakan pembelajaran pada Pendidikan Sekolah Dasar (SD) dan masyarakat Sekitar, mengadakan pelatihan Bahasa Inggris, Pengajian Anak-anak, dan Penyuluhan yang berkaitan dengan permasalahan yang kami temui selama observasi.

Program dari sisi kesehatan yang telah dipersiapkan adalah melakukan Penyuluhan Hipertensi, Bahaya Rokok, Cek Tensi Darah dan Perilaku Hidup Bersih dan Sehat (PHBS)

Program dari sisi Ekonomi yang telah dipersiapkan adalah melakukan bakti sosial dam pelatihan membuat nuget pisang

Program dari sisi Teknik yang telah dipersiapkan adalah pembuatan plang jalan, pengenalan komputer, dan renovasi MCK.

\section{Potensi dan Permasalahan yang Dihadapi}

1) Potensi masyarakat Desa Cibuntu

Masyarakat Desa Cibuntu pada umumnya berlatar belakang pertanian. Melihat dari mata percaharian masyarakat tersebut dapat disimpulkan bahwa potensi dari Kampung Ciboyong adalah pada bidang pertanian. Jika bidang ini dapat di kembangkan maka akan menjadi sangat potensial bagi masyarakat setempat.

2) Permasalahan di Desa Cibuntu dalam bidang:

Pendidikan

1. Belum memiliki bangunan Madrasah Ibtidaiyah

2. Kurangnya perhatian orang tua terhadap pendidikan

3. Kurangnya pengawasan orang tua terhadap anak

4. Fasilitas dan bangunan pendidikan yang masih minim untuk menunjang Kegiatan Belajar Mengajar (KBM)

Kesehatan

1. Belum memiliki bangunan puskesmas

2. Hanya punya 1 posyandu dan belum memaksimalkan fungsi Posyandu itu sendiri

3. Masih kurangnya kesadaran masyarakat dalam kesehatan diri

4. Fasilitas posyandu yang kurang memadai.

5. Kurangnya pengetahuan masyarakat mengenai manfaat dari Posyandu (imunisasi, menimbang balita, pemberian vitamin A dan lain-lain)

Lingkungan

1. Pengelolaan sampah yang buruk

2. Belum ada tempat penampungan dan pengelolaan sampah.

3. Kebiasaan masyarakat dalam MCK di sembarang tempat 
4. Kurangnya sinergi masyarakat untuk gotong royong dan buang sampah pada tempatnya

Ekonomi

1. Belum ada koperasi peminjaman uang

2. Warga yang mayoritas bersifat konsumtif

Solusi yang Ditawarkan

1. Identifikasi

Pemberdayaan masyarakat di Desa Cibuntu dalam Bidang Kesehatan, Bidang Pendidikan, Bidang Teknik, dan Bidang Ekonomi.

2. Perumusan Masalah

Bidang pendidikan

Mengadakan pengajian anak-anak setiap hari Senin s/d Jum'at yang bertujuan untuk meningkatkan pengetahuan dalam ilmu agama dan selain itu kami mengadakan les bahasa Inggris setiap satu kali dalam seminggu di posko kami yang berlokasi di Kontrakan Bapak $\mathrm{H}$. (depan pabrik Minuman

Cincau) untuk anak-anak SD, PAUD yang berada di sekeliling posko. Dan di akhir kegiatan pengajian dan les bahasa Inggris, kami pun mengadakan Lomba hafalan surat-surat pendek untuk mengetahui pemahaman anak-anak selama ini setelah kami berikan pengetahuan dalam ilmu agama dan bahasa Inggris tersebut.

Bidang Kesehatan

Dalam bidang kesehatan sendiri kita mengadakan Penyuluhan PHBS (pola hidup bersih dan sehat) untuk anak SD , serta kami mengadakan Penyuluhan Bahaya Rokok untuk MTs. Dan kami pun mengadakan Cek Tensi Darah untuk masyarakat di Kp. Ciboyong.
Bidang Lingkungan dan teknik

Program yang kami rencanakan adalah kerja bakti membersihkan daerah sekitar Kp. Ciboyong dengan sebutan Jum'at Bersih. Program ini terlaksana, kerja bakti kami lakukan setiap Jum'at jam 7 pagi. Tetapi tidak ada masyarakat yang berpartisipasi membantu membersihkan dikarenakan kesibukan pekerjaan masing-masing keluarga. Ketiga kami juga melakukan renovasi MCK mulai dari tahap Pengecoran lantai, pemasangan genteng kaca, pemasangan pipa dan kloset, dan Pengecatan MCK di Kp. Ciboyong.

Bidang Ekonomi

Di Bidang ekonomi sendiri kita ingin mengadakan bakti sosial di Kp. Ciboyong,agar warga Ciboyong peduli terhadap sesama, Kedua kami mengadakan pelaihan membuat nuget pisang agar warga ciboyong dapat termotivasi dalam berwirausaha.

\section{Geografis}

Secara geografis Desa Cibuntu berada di Kecamatan Ciampea Kabupaten Bogor, Provinsi Jawa Barat yang meliputi:

Batas Wilayah

Sebelah Utara : Desa Cicadas

Sebelah Selatan : Desa Ciampea Udik

Sebelah Barat : Desa Ciaruteun Udik

Sebelah Timur : Desa Cinangka

\section{Luas Wilayah}

a) Jalan : 1.65. Ha

b) Tanah Pemukiman : 42. Ha

c) Lahan Sawah dan Ladang : 57,45. Ha

d) Prasarana Umum : 2,1. Ha

e) Empang : 5,7. Ha

f) Tanah Pemakaman : 3,1. Ha 


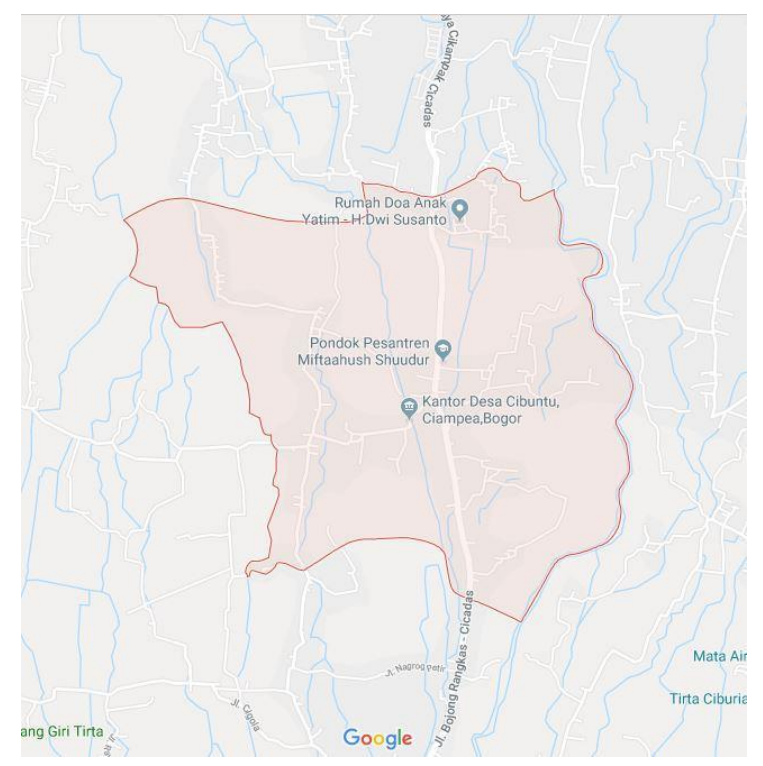

\section{Keadaan Topografi Desa}

Secara umum keadaan topografi Desa Cibuntu adalah daerah dataran tinggi dengan ketinggian dari permukaan laut 510 Meter. Suhu rata- rata Desa Cibuntu berkisar $17-18^{\circ}$. Desa Cibuntu terdiri dari 7 Rukun Warga (RW) dan 26 Rukun Tetangga (RT). Iklim di Desa Cibuntu, sebagaimana Desa- desa lain di Wilayah

Indonesia mempunyai iklim kemarau dan penghujan. Iklim yang mempengaruhi Desa Cibuntu adalah adalah ilklim penghujan yang membantu warga Desa Cibuntu yang mayoritas berprofesi sebagai petani agar kebun mereka bisa diberi air sehingga dapat dipanen tepat waktu.

\section{Demografi}

Keadaan Sosial dan Budaya Kondisi sosial Desa Cibuntu terdiri dari masyarakat asli (Pribumi) yang ditambah dengan penduduk pendatang. Desa Cibuntu terdiri dari:

1. Jumlah penduduk per Bulan Januari 2018 berdasarkan kependudukan dengan jumlah jiwa:

\begin{tabular}{|c|c|c|}
\hline Laki- laki & Perempuan & Jumlah \\
\hline 4662 Jiwa & 4986 Jiwa & 9648 Jiwa \\
\hline
\end{tabular}

2. Pendidikan

Jumlah Penduduk berdasarkan Pendidikan

\begin{tabular}{|c|l|c|}
\hline No & Tingkat Pendidikan & Jumlah \\
\hline 1 & Taman Kanak- kanak & 892 \\
\hline 2 & Sekolah Dasar & 2.016 \\
\hline 3 & SLTP & 2.681 \\
\hline 4 & SLTA & 302 \\
\hline 5 & $\begin{array}{l}\text { Akademi (D1, D2, } \\
\text { D3) }\end{array}$ & 27 \\
\hline 6 & S1, S2, S3 & 211 \\
\hline 7 & Pondok Pesantren & 885 \\
\hline 8 & Madrasah & 929 \\
\hline 9 & $\begin{array}{l}\text { Pendidikan } \\
\text { Keagamaan }\end{array}$ & 78 (plus 25 \\
\hline 10 & Kuru ngaji) \\
\hline & JUMLAH Ketrampilan & 17 \\
\hline
\end{tabular}

\section{Kondisi Masyarakat}

Sumber Daya Manusia (SDM) yang ada di wilayah Desa Cibuntu Kecamatan Ciampea, mempunyai potensi dalam bidang pangan. Dikarenakan mayoritas warga bekerja sebagai petani maka pengembangan usaha dikhususkan di bidang pertanian, Kelompok Usaha Tani. Hal ini disebabkan karena mata pencaharian Desa Cibuntu adalah petani. 
METODE PELAKSANAAN

\begin{tabular}{|c|c|c|c|c|c|c|}
\hline \multirow{2}{*}{ NO } & KEGIATAN & \multicolumn{3}{|c|}{ AGUSTUS } & SEP \\
\hline & & 1 & 2 & 3 & 4 & 1 \\
\hline 1. & Penyusunan Rencana Kegiatan & & & & & \\
& & & & & \\
\hline 2. & Sosialisasi Kegiatan KKN & & & & \\
\hline 3. & Kegiatan Les Bahasa Inggris & & & & \\
\hline 4. & Pengajian Anak- Anak & & & \\
\hline 5. & Lomba hapalan surat pendek & & & & \\
\hline 6. & Penyuluhan Edukasi PHBS & & & & \\
\hline 7. & Penyuluhan Kesehatan hipertensi & & & \\
\hline 8. & & & & \\
\hline 9. & Penyuluhan bahaya rokok & & & \\
\hline 10. & Pawai obor & & & \\
\hline
\end{tabular}

\section{Metode Pendekatan}

Pendekatan yang digunakan dalam kegiatan ini adalah:

1. Pendekatan religius, yaitu pendekatan yang menggunakan nilai-nilai agama sebagai basis kegiatan. Pendekatan ini sangat penting karena permasalahan pemahaman radikalisme dalam masyarakat sangat dipengaruhi oleh faktor keimanan, pengalaman keagamaan, rasa tanggungjawab dan pengetahuan (Rachmawati, 2010).

2. Pendekatan organisasi, yaitu pendekatan dimana seluruh kegiatan diorganisir oleh Pondok Pesantren As Salaam dan SMP al-Ittihadiyyah. Hal ini sesuai dengan hasil penelitian Bahari (2010) dimana dia menemukan bahwa keterlibatan organisasi mempunyai pengaruh langsung terhadap toleransi.

3. Pendekatan kekerabatan, artinya bahwa pembinaan yang dilakukan senantiasa dikaitkan dalam rangka membangun kekerabatan antar

Jama'ah yang semakin memudar. Nurhayati (2005) menemukan bahwa faktor pendukung toleransi umat Islam dengan Hindu adalah adanya sistem kekerabatan.

Pendekatan berdasarkan karakter masyarakat, yakni pembinaan yang dilakukan akan disesuaikan dengan karakter masyarakat. Joyce dan Weil (1996) mengungkapkan bahwa model pendidikan yang relevan dengan perilaku sosial dan nilai adalah dengan banyak memberikan permainan peran. Hal ini dilakukan untuk memberi pengalaman riil kepada peserta didik tentang sesuatu yang dilakukan atau dirasakan oleh orang lain. Memang, dalam prakteknya, tidak seluruh aspek harus menggunakan permainan ini. Dalam beberapa hal, terdapat kegiatan-kegiatan yang hanya golongan tertentu untuk melakukannya. Sejalan dengan konsep 
Joyce dan Weil, cooperative learning yang digagas Slavin (2005) dapat digunakan untuk membangun kesadaran toleransi masyarakat. Hal ini karena penekanan dari konsep pendidikan ini adalah kerjasama yang merupakan urat nadi toleransi. Dengan demikian, model pendidikan yang akan dibangun menggunakan dua konsep utama yaitu role playing model dan cooperative learning model.

\section{Partisipasi Masyarakat dalam} Pelaksanaan Program

Partisipasi masyarakat yang dapat dilakukan dalam kegiatan ini adalah sebagai berikut:

1. Berkumpul berama ibu - ibu pengajian untuk bersilaturahim mengenai perkenalan kami, tujuan KKN dan program kerja yang akan dilaksanakan di wilayah tersebut

2. Tokoh masyarakat mendukung program kerja yang telah dibuat dengan memberikan motivasi kepada kami.

3. Memberikan izin kepada kami mulai dari renovasi MCK, Pengajian, Les Bahasa Inggris, Pelatihan komputer , Penyuluhan kesehatan dan bakti sosial.

4. Masyarakat ikut berperan dalam menyukseskan semua program kerja yang telah dibuat.

\section{Langkah Evaluasi}

Evaluasi yang akan dilakukan terdiri dari:
1. Evaluasi proses, yang terkait dengan perencanaan, pelaksanaan dan monitoring kegiatan. Evaluasi proses akan dilakukan setiap pekan bersama dengan teman - teman

2. Evaluasi hasil, yang akan dilaksanakan setelah kegiatan dilaksanakan.

Evaluasi hasil ditujukan untuk menguji pemahaman anka-anak mengenai ilmu Agama, Bahasa Inggris, pengetahuan PHBS, dan Kesehatan Hipertensi. Evaluasi hasil dilihat dari hasil lomba yang dibuat yaitu Lomba hapalan surat pendek di bidang pendidikan. Di dapatkan hasil yang sangat memuaskan, dapat dilihat dari perolehan nilai yang sangat baik. Dan untuk penyuluhan kesehatan evaluasi hasil dilihat dari hasil pre-test dan post-test.

3. Evaluasi dampak

a. Terciptanya kader-kader baru untuk melanjutkan kegiatan Les Bahasa Inggris.

b. Terciptanya suasana MCK yang baru guna untuk meningkatkan kenyamanan masyarakat terhadap mandi cuci kakus

c. Meningkatkan kesadaran masyarakat untuk selalu peduli dan merawat MCK

d. Siswa/i dapat mengetahui dampak dari cara mencuci tangan dengan baik dan benar (PHBS) 


\section{HASIL DAN PEMBAHASAN}

\section{Bidang Pendidikan}

Ada beberapa program yang kami lakukan pada bidang pendidikan diantaranya:

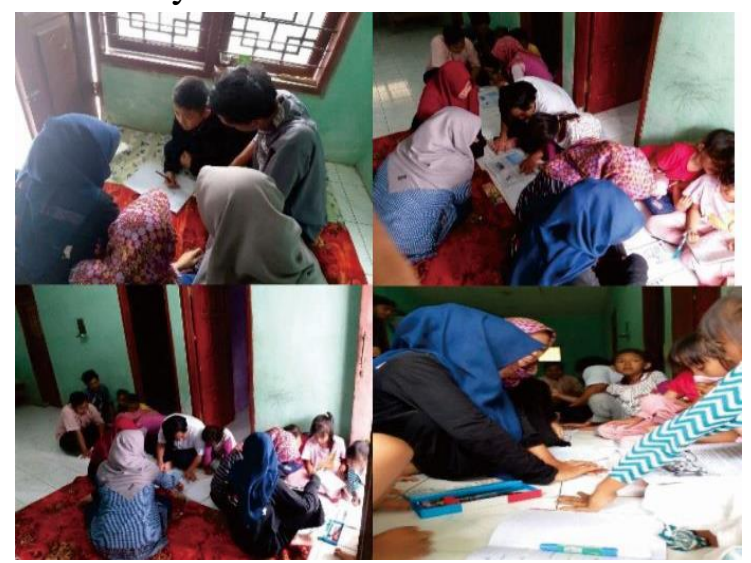

a. Pelatihan Bimbel

Bimbel dilakukan dari hari Senin sampai dengan Jum'at, dimulai pukul 14.0015.00. Bimbel yang dilaksanakan adalah semua pelajaran. Materi yang disampaikan diantaranya pelajaran Bahasa Inggris, Matematika, Bahasa Arab, Bahasa Indonesia, Bahasa Sunda, Ilmu Pengetahuan Sosial (IPS).

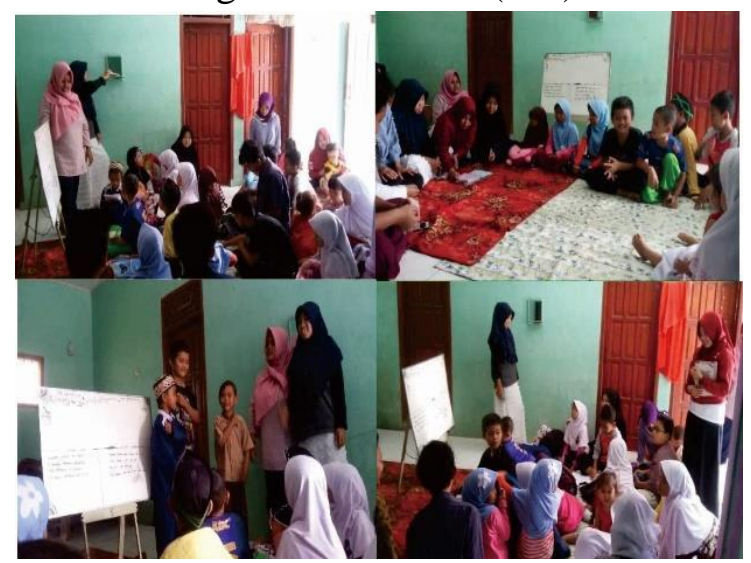

\section{b. Pengajian anak-anak}

Pengajian anak-anak dilakukan dari hari Senin sampai dengan hari Jum'at, dimulai pukul 16.00 - 17.00. Hasil yang dicapai dari kedua pelatihan sangat luar biasa, anak-anak sangat antusias dan warga sangat mendukung.

\section{Bidang Kesehatan}

Program bidang kesehatan yang telah kami lakukan adalah :

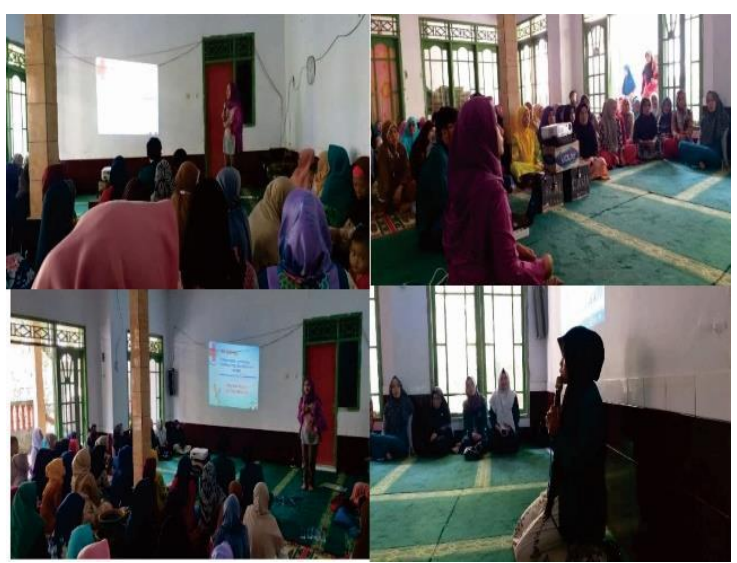

a. Penyuluhan Hipertensi

Kami melakukan penyuluhan Hipertensi di tempat Pengajian Ibu-ibu yang dilaksanakan pada hari Senin, 13 Agustus 2018 dengan sasaran Ibu-ibu yang dimulai pukul 10.00-11.00 WIB, pemateri berasal dari DPL kelompok.

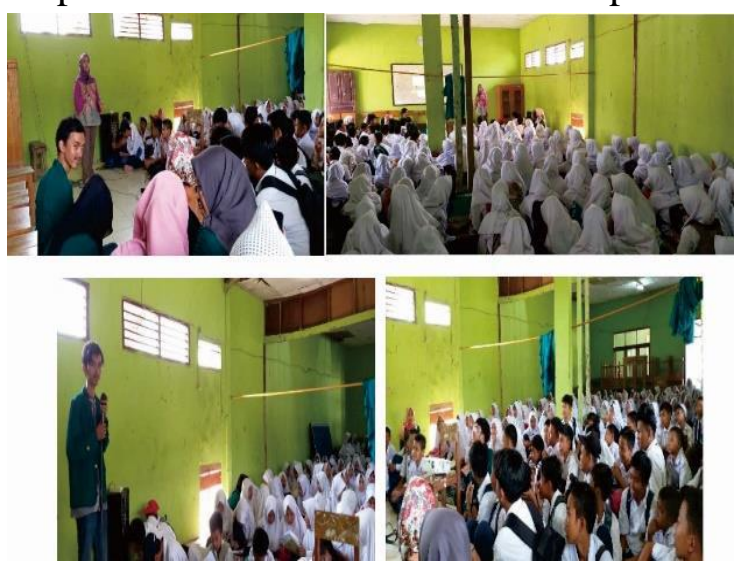

b. Penyuluhan Bahaya Rokok

Dibidang kesehatan selanjutnya, kami melakukan penyuluhan tentang bahaya rokok yang dilaksanakan pada hari Senin, 13 Agustus 2018 dengan sasaran kelas IX yang dimulai pukul 13.00-14.00 yang bertempat di MTs Nurul Ummah. Untuk pemateri, kami bekerjasama dengan DPL kelompok. 


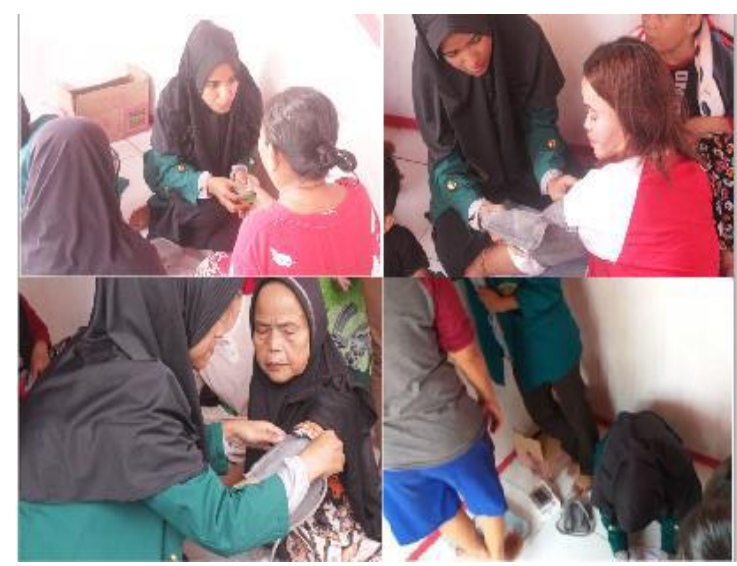

c. Cek Kesehatan

Kami melaksanakan Cek Kesehatan pada setiap hari Sabtu dimulai pukul 13.30-15.30 WIB bertempat di Posyandu RW 03 Kp. Ciboyong.

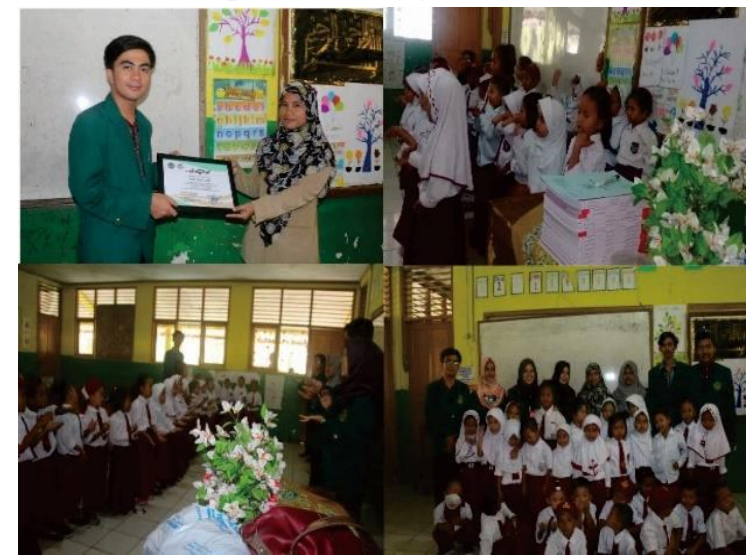

d. Penyuluhan kesehatan (PHBS)

Kami melaksanakan Penyuluhan tentang Perilaku Hidup Bersih dan Sehat (PHBS) mengenai cuci tangan dengan baik dan benar di SDN Cibuntu 03 pada hari Selasa, 21 Agustus 2018 dimulai pukul 09.00-10.30 WIB bertempat di SDN Cibuntu 03, dengan sasaran kelas I, pemateri berasal dari anggota kelompok KKN itu sendiri.

\section{Bidang Ekonomi}

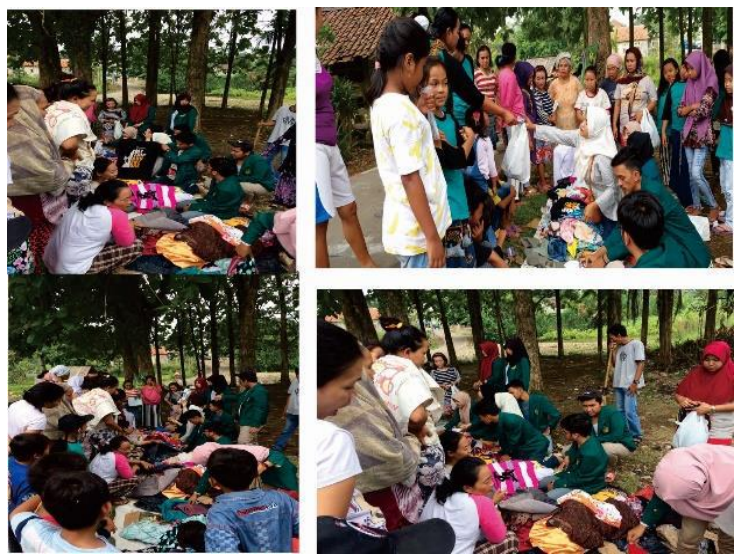

\section{a. Bakti Sosial}

Bakti Sosial Pelaksanaannya dilakukan setelah program kerja yang lain selesai. Sasaran penerima baksos yaitu perwakilan dari sepuluh orang dari setiap RT yang sudah didata sebelumnya sebagai kaum dhuafa.

\section{Bidang Lingkungan}

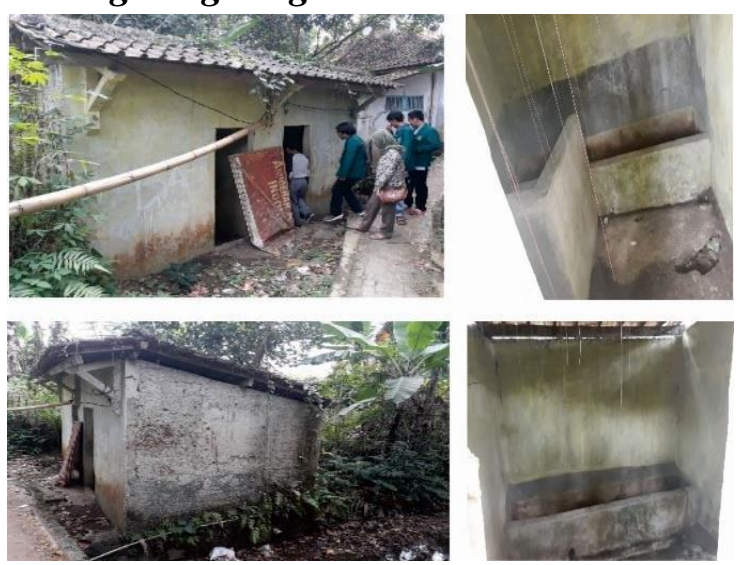

Kondisi Sebelum dan Setelah Renovasi
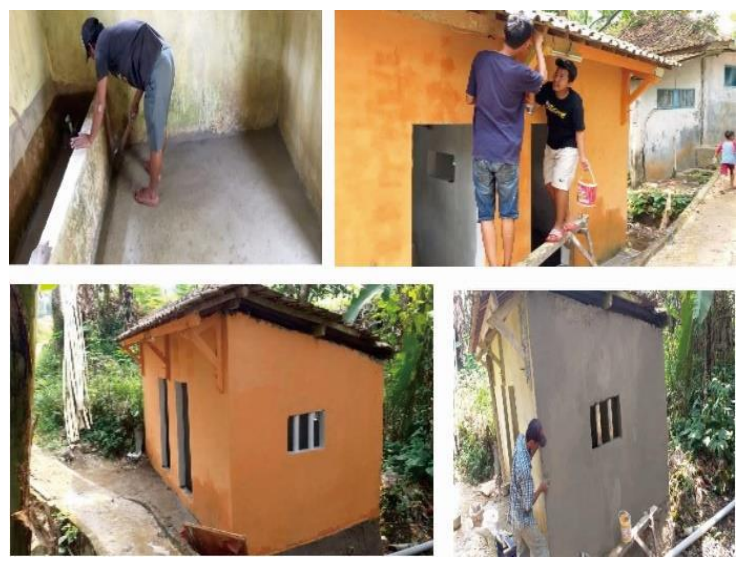

a. Renovasi MCK

Kami melaksanakan Renovasi MCK 
dimulai dari tahap Pengecoran, Pengecatan, Pembuatan keloset, dan membersihkan area mck. Yang dilakukan kondisional.

\section{Kegiatan lainnya}
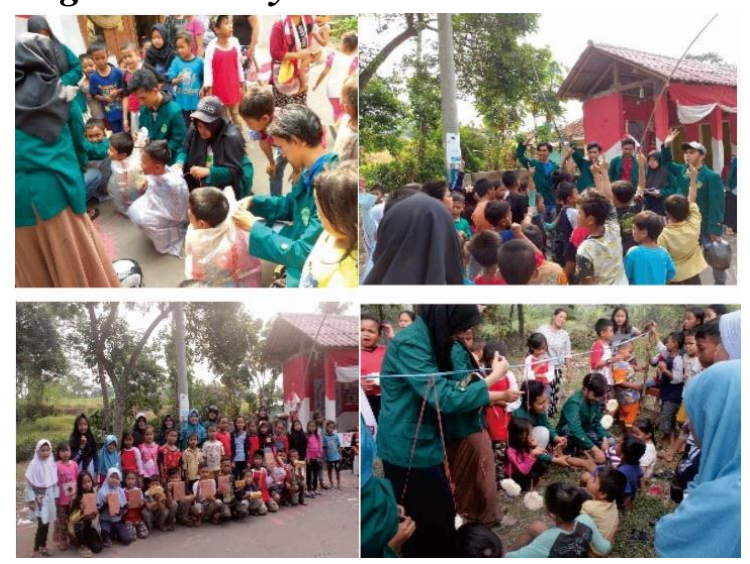

a. Memperingati HUT RI yang ke 73

Ikut berpartisipasi dalam rangka memperingati HUT RI yang ke 73 pada tanggal 17 Agustus 2018 - 18 Agustus 2018 di lapangan RT 02 RW 03. Acara tersebut sangat meriah sekali dan warga tersebut sangat antusias sekali untuk merayakan HUT RI yang ke 73

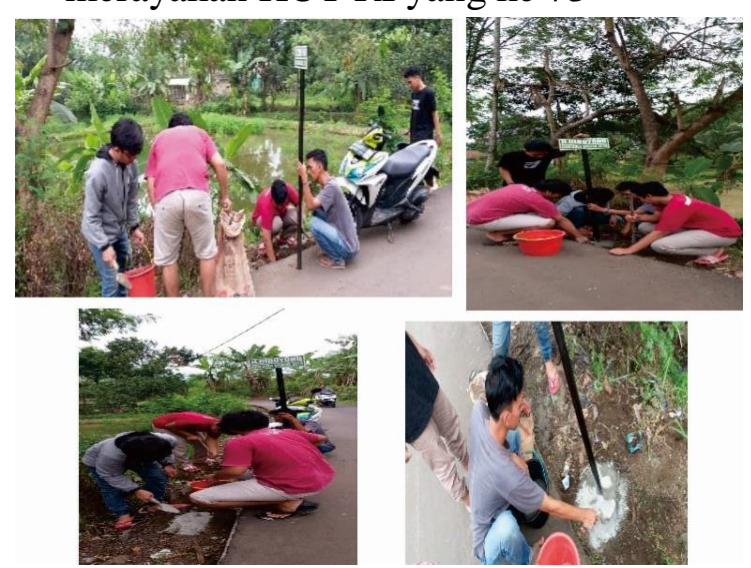

\section{KESIMPULAN}

Kegiatan Kuliah Kerja Nyata (KKN) yang diselenggarakan pihak kampus Universitas Ibn Khaldun Bogor pada 7 Agustus sampai dengan 7 September 2018 menugaskan kami sebagai mahasiswa untuk belajar menerapkan apa yang sudah kami terima dikampus pada kehidupan nyata bermasyarakat, melakukan pengabdian masyarakat selama lebih kurang selama 30 hari dengan memulai mencari data-data b. Membuat dan memasang plang nama jalan

Tidak adanya identitas yang menunjukkan kampung ciboyong, maka kami membuatkan dan memasang plang nama jalan Kampung Ciboyong dengan izin dari RT dan RW setempat.
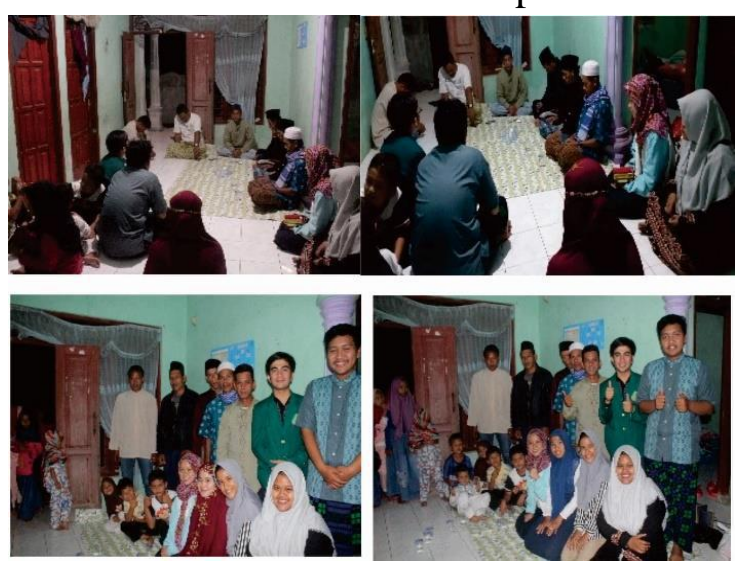

c. Mengadakan pengajian sebagai perpisahan

Acara tersebut dilakukan pada hari selasa, 4 September 2018 pada pukul $19.00-20.30$ WIB. Acara tersebut mencakup perpisahan dari kami dan dihadiri oleh pak RW 03, RT 02 dan masyarakat. yang bisa membantu terlaksananya program-program yang sudah di rencanakan, dan memastikan semua sudah terlaksana.

Berlokasi di Kampung Ciboyong RW 03, Desa Cibuntu, Kecamatan Ciampea, Kabupaten Bogor kami menerima respon yang baik, disambut dengan hangat oleh warga sekitar setelah melakukan perkenalan. Program utama yang kami 
rencanakan setelah melakukan observasi dan wawancara adalah merenovasi fasilitas mandi, cuci, kakus (MCK) yang berlokasi di RW 03, kondisi MCK yang tidak terawat karena sudah lama warga tidak menggunakannya dengan alasan kebersihan yang kurang terjaga dan kurangnya penerangan, warga lebih memilih melakukan kegiatan MCK di pinggiran sungai dibandingkan di MCK umum yang sudah sengaja disediakan. Demi menjaga kebersihan lingkungan, kesehatan warga dan mencoba mengubah pola kebiasaan warga untuk menggunakan MCK umum yang sudah disediakan.

Rencana program ini bisa berhasil terlaksana dengan bantuan dan kerjasama dari berbagai pihak khususnya warga Kampung Ciboyong RW 03. Terima kasih banyak kami ucapkan kepada pihak-pihak yang sudah ikut membantu dan semoga bisa selalu terjaga dan bermanfaat bagi semua warga.

\section{SARAN}

Pengenalan wawasan tentang Kuliah Kerja Nyata (KKN) sebaiknya dikenalkan dengan beberapa pertemuan agar mahasiswa lebih paham tahapan dan kegiatan apa yang diperlukan untuk memulai KKN. Setelah kegiatan KKN

\section{Dampak Bagi Masyarakat}

a. Membantu masyarakat dalam pelaksanaan pembangunan diberbagai bidang. Terutama di bidang pendidikan, ekonomi, sosial, agama, lingkungan dan kesehatan.

b. Meningkatkan kesadaran masyarakat untuk berperan aktif dalam peran sesuai dengan otonomi daerah.

c. Membantu masyarakat dalam mengembangkan produktifitas sumber daya pembangunan sesuai dengan fasilitas yang dimiliki.

d. Menyadarkan masyarakat untuk bekerjasama menjaga kebersihan terhadap MCK

e. Menambahkan pengetahuan kepada SISWA/I mengenai cara mencuci tangan dengan baik dan benar di air mengalir.

f. Menambahkan pengetahuan kepada warga mengenai dari dampak HIPERTENSI.

terlaksana, akan lebih baik apabila ada pengawasan jangka panjang ke lokasi KKN untuk memastikan apa yang sudah di tanam saat KKN masih bermanfaat bagi warga atau malah sebaliknya masih terawat atau tidaknya MCK yang sudah direnovasi 


\section{REFEREENSI}

Rosyadi A. Rahmat \& Prasetya Eska Perdana, Petunjuk Pelaksanaan KKN Tematik Terintegrasi 2018 Universitas Ibn Khaldun Bogor, Bogor: UIKA Prees. Tahun 2018.

Profil Desa Cibuntu Kecamatan Ciampea Kabupaten Bogor Tahun 2017.

Laporan Kelompok KKN 39 UIKA. Tahun 2017 https://www.dautic.com/definisi-komputer$\underline{\text { menurut-para-ahli/ }}$

http://definisipengertian.net/pengertianhardware-software-dan-brainware/

https://www.youtube.com/watch?v=NZW6 MoEMwDY

$\underline{\text { http://cogito.unklab.ac.id/index.php/cogito/ }}$ article/download/76/59 